Session FA2-1

\title{
A Course Sequence in High Frequency Electronics with Hands-On Laboratory Experiences
}

\author{
Charles Baylis, Randall Jean \\ Wireless and Microwave Circuits and Systems Program \\ Department of Electrical and Computer Engineering \\ Baylor University
}

\begin{abstract}
This paper describes the development of a course sequence in High Frequency Electronics at Baylor University. This sequence has been designed to provide students with a balanced learning experience consisting of classroom theory, CAD design, and hands-on measurement experience. The first semester course consists of lectures in basic RF/microwave theory and passive circuits combined with weekly hands-on and computer-aided design laboratory experiences. The second semester course consists of lectures on active $\mathrm{RF} / \mathrm{microwave}$ circuits and provides the culmination of the sequence with an amplifier design project. The course has provided an effective means of training students both in theory and practical working knowledge in the subject, while efficiently utilizing the microwave faculty of the department.
\end{abstract}

\section{Introduction}

Significant demand has been generated throughout the years from employers in the radiofrequency (RF) and microwave industry that educational programs deliver new engineers that are firmly grounded in theory, experienced in applicable CAD software tools, and well-versed in the use of common lab equipment such as vector network analyzers (VNAs) and spectrum analyzers (SAs). Many universities have documented efforts to include hands-on exposure to microwave laboratory equipment in their classes. Fusco and Stewart described a course including laboratory exercises including a microwave link, a superheterodyne receiver, a Gunn oscillator, and a scaled antenna, complemented with the use of microwave CAD tools [1]. UCL Belgium created a microwave education program that requires undergraduate students to become involved in all phases of the microwave design cycle: design, construction, and measurement [2]. Dedicated laboratory courses have been the successful vehicle to provide the hands-on experiences at some universities, such as the University of South Florida (USF) [3], with tremendous success. While the idea of a dedicated laboratory course in microwave engineering is attractive, it is difficult to integrate such a course into an emerging curriculum with limited resources. The Baylor Electrical and Computer Engineering Department is in a period of significant growth, but at present, the department faculty numbers a mere eleven, with only two members presently teaching RF/microwave and electromagnetics courses. A second issue that must be tackled is how to teach both passive and active circuit design techniques. Many universities utilize a twocourse sequence (first semester: passive, second semester: active), but in some cases both active and passive circuits are taught in the same course [4]. After careful planning and discussion, it was decided to convert an existing course into a new two-semester sequence in High Frequency Electronics, with the first semester covering $\mathrm{RF} /$ microwave circuit theory and passive microwave circuit design, and the second semester covering microwave amplifier design. The sequence is taught at the graduate level, with enrollment open to qualified undergraduates. The first course in

Proceedings of the 2009 ASEE Gulf-Southwest Annual Conference

Baylor University

Copyright $\Subset$ 2009, American Society for Engineering Education 
the new sequence continues to operate in a lecture/laboratory format. The infusion of hands-on laboratory exercises has been used over the last three years of teaching this course with tremendous success. For Fall 2008, the course consisted of a two-hour lecture and one three-hour laboratory session each week, with the course credit hours remaining at three. The combined lecture/lab offering has been assisted by generous contributions from the USF faculty who developed the WAMI Lab and RF/Microwave Circuits courses, which have been adapted as hardware and software lab experiences for the Baylor course and used in Fall 2008, and by Agilent Technologies [5] which donated Advanced Design System software for use in the course.

\section{High Frequency Electronics I}

The first-semester course, High Frequency Electronics I, covers the topics of transmission line theory, Smith Charts, microwave network analysis, matching network design, couplers, filters, resonators, diodes, and mixers. The laboratory portion of the course is synchronized with the lectures so that the lecture topics are reinforced with interesting CAD design and measurement experiences. The textbook used for the course is Microwave Engineering by Pozar [6]. When this course has been offered, the instructor has selected and/or created laboratory exercises to complement the lecture topics. For the Fall 2008 semester, the laboratory exercises were derived from exercises originally written by Drs. Larry Dunleavy and Tom Weller for the USF Wireless Lab and RF/Microwave Circuits I courses [3]. For purposes of this paper, the Fall 2008 semester is used for discussion. A regular week consists of a 3-hour laboratory period and a two-hour lecture. Table 1 gives a week-by-week breakdown of the topics addressed in the laboratory and lecture.

The semester opens with a discussion of transmission lines and Smith Charts. To introduce the laboratory equipment, the first laboratory experience consists of a comparison of time- and frequency-domain measurements. This allows students to compare prior knowledge of timedomain measurements using an oscilloscope, previously experienced in the circuits laboratory, to the use of a spectrum analyzer for frequency-domain measurements, which is a new topic to most of the students entering the course. The second laboratory experience in vector network analyzer (VNA) measurements coincides with the lecture topic on network analysis, during which students learn how to calculate S-parameters of electrical two-port networks that contain resistors and transmission lines. At this point in the semester, students have obtained a basic grasp of microwave basic theory and also have learned techniques of measurement equipment.

The course then turns to topics of passive circuit design. Matching networks are discussed, including two-element lumped "L-section" networks and distributed, single-stub matching networks. Agilent Technologies' Advanced Design System (ADS) is introduced to the students in Lab 3, which involves the optimization of a parasitic element model. This software laboratory introduces students to principles of non-ideal component behavior at high frequencies due to device parasitics. This topic is re-addressed in other laboratory exercises, including the filter design and construction that occurs later in the semester. In Lab 4, students design, simulate, and construct a quarter-wave impedance transformer. Each team is given a different cutoff frequency. Each design is fabricated using an LPKF milling machine located in the lab. Electromagnetic (EM) simulation is introduced in Lab 5 through Momentum, the EM simulator that is included within ADS. Students perform an EM simulation on a radial stub.

Proceedings of the 2009 ASEE Gulf-Southwest Annual Conference

Baylor University

Copyright $\Subset$ 2009, American Society for Engineering Education 
Table 1. Fall 2008 Approximate Week-by-Week Laboratory and Lecture Topics for High Frequency Electronics I

\begin{tabular}{|c|c|c|}
\hline Week & Laboratory & Lecture \\
\hline 1 & Introduction; Syllabus & Traveling Waves, Transmission Lines \\
\hline 2 & NO LAB: LABOR DAY & Transmission Lines \\
\hline 3 & $\begin{array}{l}\text { Lab 1: Time and Frequency Domain } \\
\text { Measurements }\end{array}$ & The Smith Chart \\
\hline 4 & $\begin{array}{l}\text { Lab 2: Vector Network Analyzer } \\
\text { Measurements }\end{array}$ & $\begin{array}{l}\text { Quarter-Wave Transformer, } \\
\text { Mismatches, Impedance and }\end{array}$ \\
\hline 5 & $\begin{array}{l}\text { Lab 3: Basic Operations Using Advanced } \\
\text { Design System Software }\end{array}$ & S-Parameters \\
\hline 6 & $\begin{array}{l}\text { Lab 4: Quarter-Wave Impedance } \\
\text { Matching (Week 1) }\end{array}$ & $\begin{array}{l}\text { S-Parameters, ABCD Parameters, } \\
\text { Lumped- Element Impedance Matching }\end{array}$ \\
\hline 7 & $\begin{array}{l}\text { Lab 4: Quarter-Wave Impedance } \\
\text { Matching (Week 2) }\end{array}$ & Single-Stub Tuning \\
\hline 8 & $\begin{array}{l}\text { Lab 5: Circuit Tuning and } \\
\text { Electromagnetic }\end{array}$ & $\begin{array}{l}\text { Quarter-Wave Transformer, Theory of } \\
\text { Small Reflections, Binomial }\end{array}$ \\
\hline 9 & MIDTERM EXAM & $\begin{array}{l}\text { Basic Coupler Properties, } \\
\text { Quadrature Hybrid Coupler }\end{array}$ \\
\hline 10 & Lab 6: Quadrature Hybrid Coupler & $\begin{array}{l}\text { Coupled-Line Coupler; Wilkinson } \\
\text { Divider, T-Junction Coupler }\end{array}$ \\
\hline 11 & Lab 7: Microstrip Coupled-Line Coupler & $\begin{array}{l}\text { Filter Design Using the Insertion } \\
\text { Loss Method }\end{array}$ \\
\hline 12 & Lab 8: Lumped-Element Low-Pass Filter & $\begin{array}{l}\text { Filter Transformations, Stepped } \\
\text { Impedance Low-Pass Filters }\end{array}$ \\
\hline 13 & $\begin{array}{l}\text { Lab 9: Stepped-Impedance Low-Pass } \\
\text { Filter }\end{array}$ & RF Diodes \\
\hline 14 & NO LAB: THANKSGIVING WEEK & Mixers \\
\hline 15 & Lab 10: Mixer Measurements & $\begin{array}{l}\text { Mixers in Communication Systems, } \\
\text { Final Exam Review }\end{array}$ \\
\hline 16 & FINAL EXAM & - \\
\hline
\end{tabular}

Couplers are then discussed in the lecture as a microwave method for power combining and division. Two laboratory exercises are associated with coupler design. In Lab 6, a quadrature hybrid coupler is simulated using ideal transmission line models and then using built-in microstrip models, including models for line edges and corners. Students compare the ideal and microstrip models and are able to observe the results of accounting for electric field fringing effects from corners in microstrip circuits. In the second coupler lab (Lab 7), students simulate a coupled-line coupler and fabricate their designs using the milling machine. They then measure the S-parameters of the coupler by attaching SMA-to-microstrip adapters to the 59 mil FR4 board and connecting to the VNA ports two ports at a time (50 ohm terminations are used for the remaining ports). The measurement results are compared to the simulations.

The discussion next turns to filters, where students use tables of prototype elements tabulated to achieve maximally flat (Butterworth) and equal ripple (Chebyshev) characteristics. Students learn to use these tables to design low-pass, high-pass, bandpass, and bandstop filters. Two filter design laboratories are performed. The first is a lumped-element low-pass filter design (Lab 8).

Proceedings of the 2009 ASEE Gulf-Southwest Annual Conference

Baylor University

Copyright $\left({ }_{0}\right.$ 2009, American Society for Engineering Education 
Students design Butterworth filters at different cutoff frequencies using the prototype element values, simulate the design using ideal lumped components and microstrip transmission-line models, and then solder the components onto prefabricated filter boards and measure the twoport S-parameters of the filter. Students have a chance to observe that the S-parameters of the filter deviate from ideal characteristics due to parasitics in the lumped components: for example, capacitance due to the package of an inductor tends to "short out" the inductor at high frequencies, causing a low-pass filter to actually pass some high frequencies. The next laboratory exercise (Lab 9) involves the design, fabrication, and testing of a distributed-element, stepped-impedance lowpass Chebyshev filter. The students perform designs, simulate the design in ADS, fabricate the board using the LPKF milling machine, and measure the S-parameters using the VNA.

The final part of the course includes discussion of diodes, mixers, and communication system principles such as the image frequency. These principles are taught from the viewpoint of frequency conversion: the diode is presented as a nonlinear device. The mathematics of frequency conversion is explained using the squarelaw model for the diode. Finally, the principle of frequency conversion using a mixer is examined in the context of a communication system. Calculations of conversion loss, RF-to-IF isolation, and LO-to-IF isolation are emphasized, as well as the topic of the image frequency and the need to reject this frequency prior to the mixer in a communication system. The final laboratory of the semester, Lab 10, includes measurement of a Mini-Circuits ZFM-4 mixer. Students learn the necessity of establishing accurate reference planes for power measurements by correcting for appropriate cable losses. A spectrum analyzer is used to measure conversion loss, as well as RF-to-IF isolation, of a mixer at RF frequencies of 700, 800, and $900 \mathrm{MHz}$ with a local oscillator (LO) frequency of $1 \mathrm{GHz}$. Students also measure the RF-to-IF isolation using VNA measurement and compare the results to the spectrum analyzer measurement. This exercise trains students in verifying measurement results by using independent methods, a technique very important in the microwave measurement field.

Several concerns surfaced at the beginning of the semester in teaching the course using a combined lecture-laboratory approach: (1) The two hours of lecture per week would not be sufficient to teach all of the concepts. (2) The laboratory exercises along with completing homework assignments and preparing for weekly quizzes and midterm/final exams would overwhelm the students. At the conclusion of the semester, it was found that students, based on the high exam scores obtained, did comprehend the material and that the laboratory exercises were not overwhelming to the students. The first concern was addressed by taking a focused approach at each topic in the lectures. Topics that were covered in each category were thoroughly illustrated through examples presented in the class. The second concern was alleviated by not requiring pre-laboratory reports and condensing the post-laboratory reports into a half-page summary and providing the answers to questions specified in the laboratory write-up (The approach on the post-laboratory reports was taken from the USF WAM I Lab [1], where it has also been successfully used). This approach allows students to spend time considering important issues, but does not force them to spend large amounts of time drafting, writing, formatting, and editing extensive pre- and post-laboratory reports, techniques that are taught in other courses within the curriculum.

This course, by utilizing a balanced lecture/laboratory approach, provides a solid framework for developing microwave engineers by providing familiarity with microwave theory and then enforcing this theory by providing practical laboratory experiences that support the lecture topics. It also sets the stage for the amplifier design project to come in the second course of the sequence, High Frequency Electronics II. 


\section{High Frequency Electronics II}

The second course in the sequence, taught for the first time in Spring 2009, covers topics in $\mathrm{RF} /$ microwave active circuit design. This course builds on the theoretical and experimental framework laid in the first course. Taught in the Spring semester, this course uses a perhaps more traditional 3 hours of lecture per week, but utilizes software exercises to support the lecture topics and includes a six to eight week amplifier design project involving design, simulation, construction, and measurement of an RF/microwave power amplifier. This course uses the book Microwave Transistor Amplifiers by Gonzalez [7]. Table 2 shows an approximate schedule for topical coverage.

Table 2. Week-by-Week Topics for High Frequency Electronics II

\begin{tabular}{|c|l|}
\hline \multicolumn{1}{|l|}{ Week } & \multicolumn{1}{c|}{ Topics } \\
\hline 1 & Introduction; ZY Smith Chart \\
\hline 2 & L-Section Impedance Matching Networks, Microstrip Matching Networks \\
\hline 3 & Power Gain, VSWR, Stability \\
\hline 4 & Constant-Gain Circles in Unilateral and Bilateral Conditions \\
\hline 5 & Available Power Gain Circles, Constant VSWR Circles \\
\hline 6 & BJT and FET DC Characteristics, DC Bias Networks \\
\hline 7 & Noise in Two-Port Networks, Noise Figure Circles \\
\hline 8 & Broadband Amplifier Design, MIDTERM EXAM \\
\hline 10 & $\begin{array}{l}\text { BJT and FET AC Characteristics, Miller's Theorem, Gain-Bandwidth } \\
\text { Product, AMPLIFIER DESIGN PROJECT ASSIGNED }\end{array}$ \\
\hline 11 & Amplifier Tuning, Bandwidth Analysis, High-Power Amplifier Design \\
\hline 12 & High-Power Amplifier Design, PRELIMINARY DESIGN REVIEW \\
\hline 13 & Two-Stage Amplifier Design, Oscillation Conditions \\
\hline 14 & Sigo-Port Negative Resistance Oscillators, Oscillator Design Using Large- \\
\hline 15 & CRITICAL DESIGN REVIEW, Oscillator Configurations \\
\hline 16 & Oscillator Configurations, FINAL DESIGN REVIEW \\
\hline & \\
\hline
\end{tabular}

The second-semester course focuses essentially on designing load and source matching networks for active devices to achieve design goals such as gain, stability, noise, power, and broadband performance. The lecture topics for this course begin with a discussion of the Smith chart and introduction of the ZY Smith chart, followed by conjugate gain matching, noise, stability, and bandwidth. Oscillator design using the negative resistance method is also covered.

About halfway through the semester, following coverage of major amplifier topics, specifications are provided to students to perform amplifier designs. The students perform the designs, then simulate these ideal designs in the ADS simulator. They add levels of complexity to the simulation including transmission lines and edge effects, and parasitic models for the components. Modelithics [8] plans to donate models for use in this course to assist students in experiencing a more complete CAD-assisted design cycle. As they proceed through the simulation steps, students adjust their designs to compensate for non-ideal effects presented as the simulation complexity increases. Finally, when the design is functioning properly, and 
following a design review process similar to one the students will experience in their future careers in the industry, the student designs are fabricated using the milling machine and measured to check for specifications. A final report and, depending on the class size and time available, final presentation of the amplifier results are presented by the students.

The design project serves as a culmination of the theory learned in both semesters of the course sequence, and also serves to combine and emphasize laboratory topics learned in the firstsemester course. After completing the sequence (6 total credit hours), students will have gained theoretical and practical knowledge necessary to design, simulate, and test RF and microwave circuits. This experience will enhance their opportunity for immediate success as they begin careers in this field.

\section{The Role of the Sequence in the Baylor ECE Curriculum}

This course sequence plays an integral role in educating Baylor students to principles of wireless and microwave communications. It complements systems principles taught in the Principles of Communication course, as it introduces students of circuit design for system-level blocks introduced in this course such as amplifiers, filters, and mixers. Special attention is paid in the High Frequency Electronics sequence to emphasize the system level roles of the circuit design techniques presented. In addition, it complements the required undergraduate course in Applied Electromagnetics and another new undergraduate elective/graduate course recently developed in Advanced Electromagnetics, which focuses on teaching electromagnetic principles as applied to high- frequency circuit design.

The approach taken in combining the hands-on laboratory experiences with the theory has proven to be an efficient approach to take in the developing program at Baylor with a limited number of faculty available to teach courses in the RF/microwave/electromagnetic areas. With the aforementioned limited number of department faculty, combining the hands-on laboratory experience with the lecture has proven to allow other innovative ventures to be pursued by the microwave faculty members, such as the work of the second author in developing the course in Applied Electromagnetics and integrating antenna design topics into the Freshman Engineering course, and the work of the authors to develop an industry advisory board for the program and to organize an on-campus mini-symposium addressing wireless and microwave topics.

\section{Conclusions}

A course sequence in High Frequency Electronics incorporating theory, software experiences, and hands-on laboratories has been developed at Baylor University. The first semester sequence uses one credit hour of the course to devote to a weekly laboratory exercise that complements lecture topics. In the second semester, an amplifier design project is assigned to students. After taking these courses, students will be well-versed in the theory of RF/microwave active and passive circuit design as well as possessing practical laboratory measurement and software capabilities. 


\section{Acknowledgments}

The authors would like to thank Dr. Larry Dunleavy and Dr. Tom Weller of the University of South Florida Center for Wireless and Microwave Information (WAM I) Systems, who have graciously provided laboratory materials from their WAMI Lab and RF/Microwave Circuits courses for adaptation in the development of the Baylor course sequence. Gratitude is also extended to Agilent Technologies for the donation of Advanced Design System (ADS) software for use in Baylor's education and research program.

\section{References}

1. V. Fusco and J. Stewart, “Microwave Education in a University Engineering Department,” European Microwave Conference, pp. 426-431, Vol. 1, October 1991.

2. D. Vanhoenacker, I. Huynen, I. Lee, R. Platteborze, and A. Vander Vorst, "Microwave Undergraduate Education at UCL Belgium: From Planar Passive Components to Wide Band Tuned Devices,” European Microwave Conference, Vol. 2, October 1995, pp. 798-803.

3. T. Weller, P. Flikkema, L. Dunleavy, H. Gordon, and R. Henning, “Educating Tomorrow’s RF/Microwave Engineer: A New Undergraduate Laboratory Uniting Circuit and System Concepts,” IEEE International Microwave Symposium Digest, 1998.

4. A. Raisanen, "Microwave Education at the Helsinki University of Technology," European Microwave Conference, Vol. 2, Issue 1, October 1990, pp. 1650-1652.

5. Agilent Technologies, Santa Rosa, California, http://www.agilent.com.

6. D.M. Pozar, Microwave Engineering, Third Edition, Artech House, 2004.

7. G. Gonzalez, Microwave Transistor Amplifiers, Second Edition, Prentice Hall, 1997.

8. Modelithics, Inc., Tampa, Florida, http://www.modelithics.com.

\section{CHARLES BAYLIS}

Dr. Charles Baylis currently serves as an Assistant Professor of Electrical and Computer Engineering at Baylor University in Waco, Texas. His research interests include RF/microwave active circuit design and modeling, biological applications of microwave measurements, applied mathematical problems in microwave engineering, and engineering education techniques.

\section{RANDALL JEAN}

Dr. Randall Jean currently serves as an Associate Professor of Electrical and Computer Engineering at Baylor University in Waco, Texas. His research interests include microwave applied metrology, blood glucose analysis, and pulp stock consistency calibration. Dr. Jean is a Registered Professional Engineer in the state of Texas. 